\title{
HIV/AIDS therapy and prevention: The two solitudes
}

\author{
Jocelyne Piret PhD, Michel G Bergeron MD FRCPC
}

$\mathrm{T}$ he Joint United Nations Programme on HIV/AIDS (UNAIDS) and the World Health Organization (WHO) announced gains in the total number of people living with HIV/AIDS worldwide for the year 2007. This was attributed to the increase in access to antiretroviral therapy in low- and middle-income countries. However, nearly 7000 new cases of HIV infection occurred each day of the same year. We propose that the number of new HIV infections need to be reduced, by the use of prevention methods, to have a significant impact on the epidemic. We could better control HIV/AIDS only through the integration of therapeutic and multiple prevention strategies elaborated on a community-based approach. Prevention and treatment must be scaled up in a balanced way.

With more than 25 million deaths, HIV/AIDS is one of the most significant pandemics in recorded history. In 2007, 33 million people were living with HIV worldwide; $67 \%$ were in Africa (1). According to the UNAIDS/WHO 2008 report (2) on the global AIDS epidemic, significant gains have been obtained in several heavily affected countries by providing antiretrovirals to individuals infected with HIV. Despite these gains, nearly 7000 people still became newly infected with HIV each day. The epidemic cannot be controlled if there is no reduction in the number of new cases of HIV infection. However, available prevention strategies are accessible to fewer than one in five people at risk of contracting HIV (3). HIV/AIDS therapy and prevention are two solitudes in the fight against this disease. It is only through combined efforts of therapy and prevention that we could have a significant impact on this epidemic.

Zidovudine, the first anti-HIV drug, was the most rapidly approved drug since the creation of the Food and Drug Administration (FDA) (4). Its approval happened only six years after the discovery of HIV. In 1995, the development of protease inhibitors, which are the backbone of highly active antiretroviral therapy, changed the face of AIDS (5). In developed countries, their introduction caused a drastic decrease in the mortality and the morbidity rates associated with AIDS. However, drug-resistant HIV strains rapidly emerged. Nowadays, the rational drug design through structural biology leads to the development of new drugs acting at different levels of the virus life cycle (6). The continuous flow of new molecules in the pipeline increases the arsenal of antiHIV drugs. Now, clinicians have the possibility to switch to new cocktails of drugs in the event of therapeutic failure or drug-induced toxicity. However, none of these drugs are still able to eradicate latent virus associated with resting memory $\mathrm{T}$ cells, which constitute the reservoir of a pool of all historical strains (sensible/resistant) of a patient (7). There is no cure against HIV/AIDS yet.

The same year that zidovudine was approved, the FDA allowed condom makers to advertise that latex condoms prevented the transmission of HIV and other sexually transmitted infections (8). Male and female condoms are highly effective technologies currently available to protect individuals from the sexual transmission of HIV. Condoms have effectiveness rates ranging between $80 \%$ and $95 \%$, depending on how correctly and consistently they are used (9). However, their expanded access and use are still facing sociocultural, political, economic and structural barriers. Worldwide, it is estimated that only $9 \%$ of people at risk of acquiring HIV have access to condoms (3).

Experience in industrialized countries suggests that HIV/AIDS treatment access, if not combined with prevention, can alter people's perception of the risk of HIV, and lead to increases in risk behaviour and new infections (10). In these countries, AIDS is not as frightening as it was before highly active antiretroviral therapy - it lost its status of killer. HIV/AIDS is now assumed to be a chronic, treatable disease, although outcomes beyond 10 to 15 years of treatment are unknown. Consequently, a re-emergence of HIV/AIDS epidemic in men having sex with men has been reported (11). This re-emergence could be associated with an increased frequency of unprotected sex. The likely reasons for these high-risk behaviours are the lack of awareness of the sexual transmission of HIV and the unknown HIV infection status. With the objective to curb the number of new HIV infections, not-for-profit organizations working with populations at high risks of contracting HIV are now reinforcing the promotion of voluntary counselling and HIV testing together with education and prevention (including the promotion of condom use) campaigns. This clearly shows that treatment and prevention strategies need to be combined for a better control of the HIV/AIDS epidemic.

In 2001, the World Trade Organization's Doha (Qatar) agreement (12) (agreement on the trade-related aspects of intellectual property rights) together with nongovernmental organizations, governments of developing countries and the Global Fund to Fight AIDS, Tuberculosis and Malaria, allowed developing countries to buy drugs for lower prices or make generic drugs to meet public health crisis. In August 2007, the nevirapine tablet was the 51st anti-HIV drug approved by the FDA (13) under the President's emergency plan for AIDS relief (14). These 51 drugs can be purchased by partners of the President's emergency plan for AIDS relief as high-quality generic drugs outside the United States. Lower prices for anti-HIV drugs significantly improved access to treatment for people in poor countries, but the United

Centre de recherche en infectiologie, Université Laval, Québec, Québec

Correspondence: Dr Michel G Bergeron, Centre de recherche en infectiologie, Centre Hospitalier Universitaire de Québec, Pavillon CHUL, 2705 Blvd

Laurier, RC-709, Québec, Québec G1V 4G2. Telephone 418-654-2705, fax 418-654-2197, e-mail michel.g.bergeron@crchul.ulaval.ca

Received for publication October 28, 2008. Accepted December 8, 2008 
Nations' long-term goal of universal coverage by 2010 is still far from reachable. As of the end of 2007, close to three million people in low- and middle-income countries received antiretroviral drugs (15). This represented an increase of nearly 950,000 people who received antiretroviral therapy compared with the year before. Based on the AIDS epidemiology data for the year 2007, it can be calculated that for each person infected with HIV who received antiretroviral therapy, nearly three individuals became newly infected with the virus. HIV continues to overpass the global response, with at least $69 \%$ of infected individuals not having received antiretroviral treatment as yet.

It is estimated that approximately $80 \%$ of people living with HIV in low- and middle-income countries are still not aware of their HIV status (16). A recent survey (3) in Sub-Saharan Africa revealed that only an average of approximately $10 \%$ of women and $12 \%$ of men have been tested for HIV and were informed of their test results. It is essential to increase voluntary counselling and HIV testing to promote the access of individuals in need of antiretroviral therapy and available prevention methods to reduce the transmission of the virus to uninfected partners.

The diagnosis of HIV in infants is difficult, and only $15 \%$ (200,000 as of the end of 2007) of infected children received antiretroviral drugs (15). In Sub-Saharan Africa, most children infected with HIV have contracted the virus from their mother. Blocking mother-to-child transmission of HIV with nevirapine is one of the simplest and cheapest prevention methods available (17). However, in low- and middle-income countries, only $33 \%(500,000$ as of the end of 2007) of seropositive pregnant women received antiretrovirals to prevent the transmission of HIV to their newborn.

Worldwide, $50 \%$ of the women infected with HIV are of childbearing age. Access to contraceptive methods for the prevention of unintended pregnancies among seropositive women has also been recognized as an important and cost-effective way of preventing HIV infection in infants (18). However, in SubSaharan Africa, one in four married women have an unmet need for contraception and are, therefore, at risk of unintended pregnancy (19). For the same cost as treatment with antiretroviral drugs to prevent mother-to-child transmission, contraceptive use can avert nearly 30\% more unintended HIV-positive child births (18).

Recently, three randomized clinical trials (20-22) evaluated the effect of circumcision on the risk of acquisition of HIV among consenting, healthy adult men in Uganda, Kenya and South Africa. These trials were halted prematurely after recommendations by independent data and safety monitoring boards, when interim analyses indicated that the risk of HIV acquisition among the men randomly assigned to the circumcision arm was reduced by approximately $60 \%$. However, the implementation of male circumcision into public health policy is still delayed by many concerns, such as surgical complications, risk compensation and costs (23). An extended follow-up of the Kenya study (24) indicated that the protective effect of circumcision lasted for at least 42 months. Moreover, a recent study (25) demonstrated that circumcision did not result in increased risk behaviour. The authors suggest that male circumcision could be first integrated into a package including multiple prevention strategies, and after further evidence is obtained, it could be widely introduced and promoted.
In addition to proven HIV prevention strategies, new effective technologies, such as AIDS vaccines and microbicides, are urgent humanitarian imperatives. An AIDS vaccine could be effective in either a prophylactic or therapeutic way. Experts have calculated that a vaccine that would be $50 \%$ effective and given to just $30 \%$ of the population could reduce the number of HIV infections in the developing world by more than one-half over 15 years (26). The biology of HIV infection presents several obstacles to the development of vaccines. First, HIV has the ability to evolve and mutate rapidly to escape immune responses. Second, the existence of several HIV clades in different areas of the world poses challenges to the development of an effective universal vaccine. Because HIV-positive people who have stronger $\mathrm{T}$ cell response tend to fight the virus better, it was postulated that a vaccine that could stimulate the $T$ cell response might be able to control HIV/AIDS. To achieve this goal, Merck $\&$ Co Inc (USA) developed a vaccine, which was a mixture of three components, each made with a weakened adenovirus type 5 vector that contained either gag, pol or nef genes from HIV clade B (27). However, the vaccine was not proven to be effective in the STEP clinical trial (28). It also seemed that the vaccine increased the rate of HIV infection in individuals with previous immunity against the adenovirus vector. Analysis of the data suggested that the vaccine failure could be due to an incomplete understanding of the interaction of HIV with the host immune defense and the lack of an adequate animal model to test its efficacy (29). Because most experimental vaccines currently in the pipeline are based on a similar concept as that developed by Merck, it is now proposed to reduce support for testing these candidates in expensive clinical trials. However, scientists urged that money should instead be spent on basic scientific research aimed at finding new approaches to a vaccine through a better understanding of host immune defense and to develop an appropriate animal model for efficacy testing.

Microbicides are a broad range of user-controlled products that would help women to protect themselves from HIV. They can be developed in any form that is convenient to use such as gel, cream, foam, film, suppository or vaginal ring. A recent analysis (30) conducted at the London School of Hygiene and Tropical Medicine (United Kingdom) estimated that a microbicide that would reduce the risk of infection by $40 \%$ and that would be used by $30 \%$ of women at risk in low-income countries would avert more than two million HIV infections a year. This implies that a microbicide with relatively low effectiveness could have substantial impact against the global HIV epidemic if it is used by a significant number of women. Several candidate microbicides are now in the pipeline. However, the field of microbicides was also in a period of disappointments and setbacks, with the failure of three candidate products (nonoxynol-9, cellulose sulfate [Polidex Pharmaceuticals Ltd, Canada] and Carraguard [Population Council, USA]) (31-33). Recently, a phase II/IIB study showed that BufferGel (ReProtect Inc, USA), which maintains a mild acidity in the vagina (34), had no safety concerns, but it did not protect women against infection by HIV (35). More interestingly, in the same study, PRO 2000 (Indevus Pharmaceuticals, USA), which blocks viral entry (36), demonstrated for the first time the promise of a vaginal gel with efficacy for preventing HIV infection in women.

Second-generation microbicides based on antiretroviral agents (such as tenovofir), included in topical vaginal 
formulations or vaginal rings, are now in early phases of clinical investigation (37). However, these studies should carefully monitor for the emergence of resistance and evaluate the risk of using these drugs outside the well-controlled frame of a clinical trial.

In a report based on several studies, the Swiss Federal Commission for HIV/AIDS has postulated that individuals using antiretroviral drugs cannot transmit HIV infection through vaginal contact if they have undetectable viral loads (less than 40 copies $/ \mathrm{mL}$ ) for at least six months, if they remain adherent to their treatment regimens and if they have no sexually transmitted infections (38). This communication was at the origin of a passionate international debate between HIV experts and advocacy groups. In response to this statement, UNAIDS and WHO strongly recommended the use of HIV prevention approaches, including correct and consistent use of condoms, to prevent transmission of HIV (39). This story clearly shows that even within the frame of an excellent prognosis, treatment needs to be combined with prevention.

\section{CONCLUSION}

Several prevention strategies have been proven effective against HIV/AIDS. These include male and female condoms, voluntary counselling and testing, behaviour change, antiretroviral interventions for blocking mother-to-child transmission and for HIV pre- and postexposure prophylaxis, contraceptive methods as well as circumcision. The development of new technologies, such as AIDS vaccines and microbicides, are currently in progress. Moreover, more accessible point-of-care and rapid diagnosis development for sexually transmitted infections should be encouraged. They will lead to rapid prevention and treatment interventions, which will reduce dissemination of these diseases. The use of only one of these prevention methods may not be sufficient in the fight against HIV/AIDS. However, the use of multiple prevention approaches will have additive effects. These different options should be evaluated on the basis of the characteristics of the community to combine them in the best comprehensive prevention package for that particular group of individuals. The United Nations has committed to provide universal access to antiretroviral therapy, but the HIV/AIDS epidemic will not be controlled unless effective prevention methods are used concomitantly to alter the number of new infections. HIV/AIDS therapy and prevention lived as two solitudes for long enough. It is time to combine the efforts between therapy and comprehensive prevention packages to have a significant impact on the epidemic.

\section{REFERENCES}

1. UNAIDS/WHO. 2008 report on the global AIDS epidemic. $<$ http://www.unaids.org/en/KnowledgeCentre/HIVData/GlobalReport/ 2008/2008_Global_report.asp> (Version current at March 20, 2009).

2. UNAIDS. Substantial increases in HIV prevention efforts producing results, but not enough to turn back the epidemic. <http://data.unaids.org/pub/PressRelease/2008/20080729_gr08_ press_release_en.pdf> (Version current at March 20, 2009).

3. The Global HIV Prevention Working Group. Global HIV prevention: The access and funding gap. < http://www.kff.org/hivaids/upload/ pwg062807factsheet.pdf> (Version current at March 20, 2009).

4. Zidovudine approved by FDA for treatment of AIDS. Clin Pharm 1987;6:431-5.

5. Williams AB. New horizons: Antiretroviral therapy in 1997. J Assoc Nurses AIDS Care 1997;8:26-38.

6. De Clercq E. The design of drugs for HIV and HCV. Nat Rev Drug Discov 2007;6:1001-18.

7. Pierson T, McArthur J, Siliciano RF. Reservoirs for HIV-1: Mechanisms for viral persistence in the presence of antiviral immune response and antiviral therapy. Annu Rev Immunol 2000;18:665-708.

8. Condoms for prevention of sexually transmitted diseases. Public Health Rev 1988;16:13-20.

9. Weller S, Davis-Beaty K. Condom effectiveness in reducing heterosexual HIV transmission. Cochrane Database Syst Rev 2002;(1):CD003255.

10. Valdiserri RO. Mapping the roots of HIV/AIDS complacency: Implications for program and policy development. AIDS Edu Prev 2004; 16:426-36.

11. Jaffe HW, Valdiserri RO, De Cock KM. The reemerging HIV/AIDS epidemic in men who have sex with men. JAMA 2008;298:2412-4.

12. World Trade Organization. Declaration on the TRIPS agreement and public health. <http://www.wto.org/English/thewto_e/minist_e/ min01_e/mindecl_trips_e.htm> (Version current at March 20, 2009).

13. FDA notifications. Tentative approval for generic nevirapine tablets. AIDS alert 2007;22:118-9.

14. The United States President's Emergency Plan for AIDS Relief. <http://www.pepfar.gov/about/> (Version current at March 20, 2009).

15. World Health Organization, UNAIDS, UNICEF. Nearly three million HIV-positive people now receiving life-saving drugs. But access to prevention and treatment still lacking for millions. $<$ http://data.unaids.org/pub/PressRelease/2008/20080602_ treatment_report_en.pdf> (Version current at March 20, 2009).

16. World Health Organization, UNAIDS. Guidance on provider-initiated HIV testing and counselling in health facilities.

<http://whqlibdoc.who.int/publications/2007/9789241595568_eng.pdf> (Version current at March 20, 2009).

17. De Cock KM, Fowler MG, Mercier E, et al. Prevention of motherto-child HIV transmission in resource-poor countries: Translating research into policy and practice. JAMA 2000;283:1175-82.

18. Cates WJ. Contraception and prevention of HIV infection. JAMA 2006;296:2802.

19. Sedgh G, Hussain R, Bankole A, Singh S. Women with an unmet need for contraception in developing countries and their reasons for not using a method. Occasional Report no. 37. New-York: Guttmacher Institute, 2007.

20. Bailey RC, Moses S, Parker CB, et al. Male circumcision for HIV prevention in young men in Kisumu, Kenya: A randomised controlled trial. Lancet 2007;369:643-56.

21. Gray RH, Kigozi G, Serwadda D, et al. Male circumcision for HIV prevention in men in Rakai, Uganda: A randomised trial. Lancet 2007;369:657-66.

22. Auvert B, Taljaard D, Lagarde E, Sobngwi-Tambekou J, Sitta R, Puren A. Randomized, controlled intervention trial of male circumcision for reduction of HIV infection risk: The ANRS 1265 Trial. PLoS Med 2005;2:e298.

23. Weiss HA, Halperin D, Bailey RC, Hayes RJ, Schmid G, Hankins CA. Male circumcision for HIV prevention: From evidence to action? AIDS 2008;22:567-74.

24. Bailey RC, Moses S, Parker CB, et al. The protective effect of male circumcision is sustained for at least 42 months: Results from the Kisumu, Kenya Trial. Program and abstracts of the 17th International AIDS Conference. Mexico City, August 3 to 8, 2008. (Abst)

25. Mattson CL, Campbell RT, Bailey RC, Agot K, Ndinya-Achola JO, Moses S. Risk compensation is not associated with male circumcision in Kisumu, Kenya: A multi-faceted assessment of men enrolled in a randomized controlled trial. PLoS ONE 2008;3:e2443.

26. International AIDS Vaccine Initiative (IAVI). Estimating the impact of an AIDS vaccine in developing countries. $<$ http://www.iavi.org/viewfile.cfm?fid=35388> (Version current at March 20, 2009).

27. Shiver JW, Fu TM, Chen L, et al. Replication-incompetent adenoviral vaccine vector elicits effective anti-immunodeficiencyvirus immunity. Nature 2002;415:331-5.

28. HIV vaccine failure prompts Merck to halt trial. Nature 2008;449:390.

29. Watkins DI, Burton DR, Kallas EG, Moore JP, Koff WC. Nonhuman primate models and the failure of the Merck HIV-1 vaccine in humans. Nature Medicine 2008;14:617-21. 
30. World Health Organization. Microbicides. <http://www.who.int/ hiv/topics/microbicides/microbicides/en/> (Version current at March 20, 2009).

31. Van Damme L, Ramjee G, Alary M, et al. Effectiveness of COL1492, a nonoxynol-9 vaginal gel, on HIV-1 transmission in female sex workers: a randomised controlled trial. Lancet 2002;360:971-7.

32. Honey K. Microbicide trial screeches to a halt. J Clin Invest 2007; 117:1116.

33. Van Damme L, Govinden R, Mirembe FM, et al. Lack of effectiveness of cellulose sulfate gel for the prevention of vaginal HIV transmission. N Engl J Med 2008;359:463-72.

34. Ballagh SA, Brache V, Mauck C, et al. A phase I study of the functional performance, safety and acceptability of the BufferGel Duet. Contraception. 2008;77:130-7.

35. Abdoul Karim S, Coletti A, Richardson B, et al. Safety and effectiveness of vaginal microbicides BufferGel and 0.5\% PRO
2000/5 gel for prevention of HIV infection in women: Results of the HPTN 035 trial. 16th Conference on Retroviruses and Opportunistic Infections. Montreal, February 8 to 11, 2009. (Abst)

36. Fletcher PS, Shattock RJ. PRO-2000, an antimicrobial gel for the potential prevention of HIV infection. Curr Opin Investig Drugs 2008;9:189-200.

37. Klasse PJ, Shattock R, Moore JP. Antiretroviral drug-based microbicides to prevent HIV-1 sexual transmission. Annu Rev Med 2008;59:455-71.

38. Vernazza P, Hirschel B, Bernasconi E, Flepp M. Les personnes séropositives ne souffrant d'aucune autre MST et suivant un traitement antirétroviral efficace ne transmettent pas le VIH par voie sexuelle. Bulletin des Médecins Suisses 2008;89.

39. Pearshouse R. Switzerland: Statement on sexual transmission of HIV by people on ART. HIV/AIDS Policy Law Rev 2008;13:37-8. 


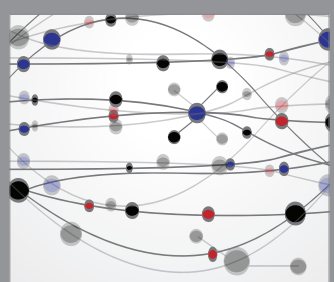

The Scientific World Journal
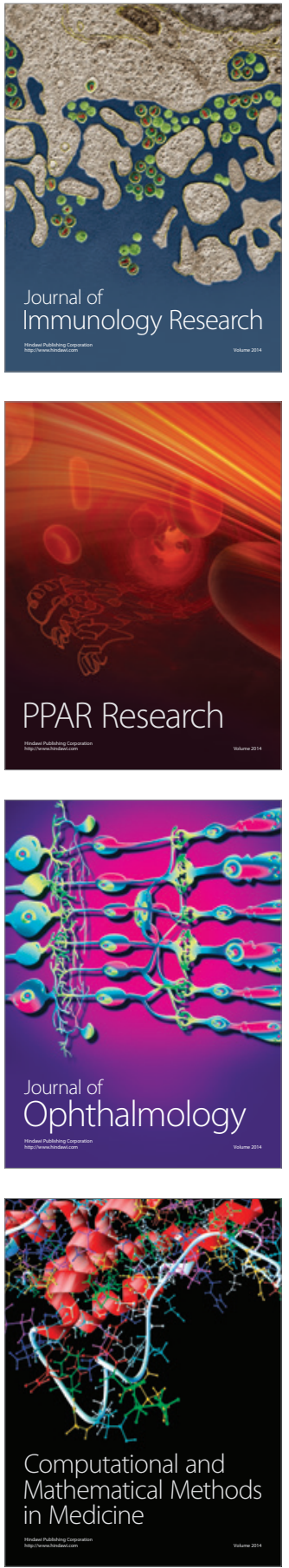

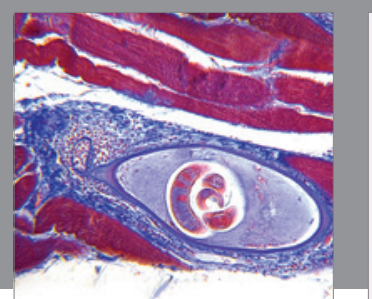

Gastroenterology Research and Practice

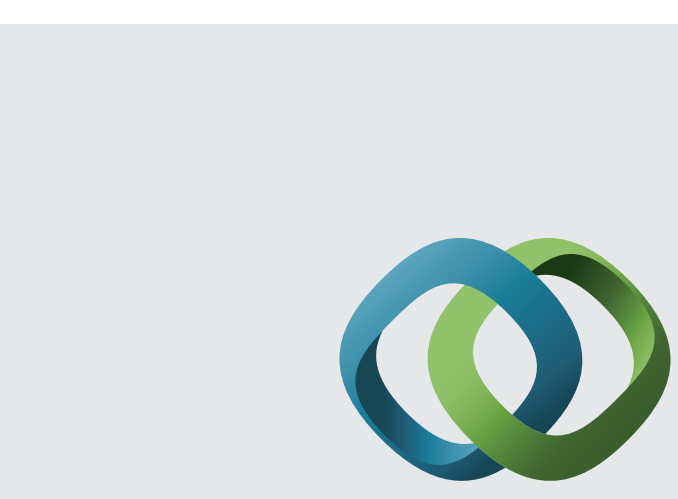

\section{Hindawi}

Submit your manuscripts at

http://www.hindawi.com
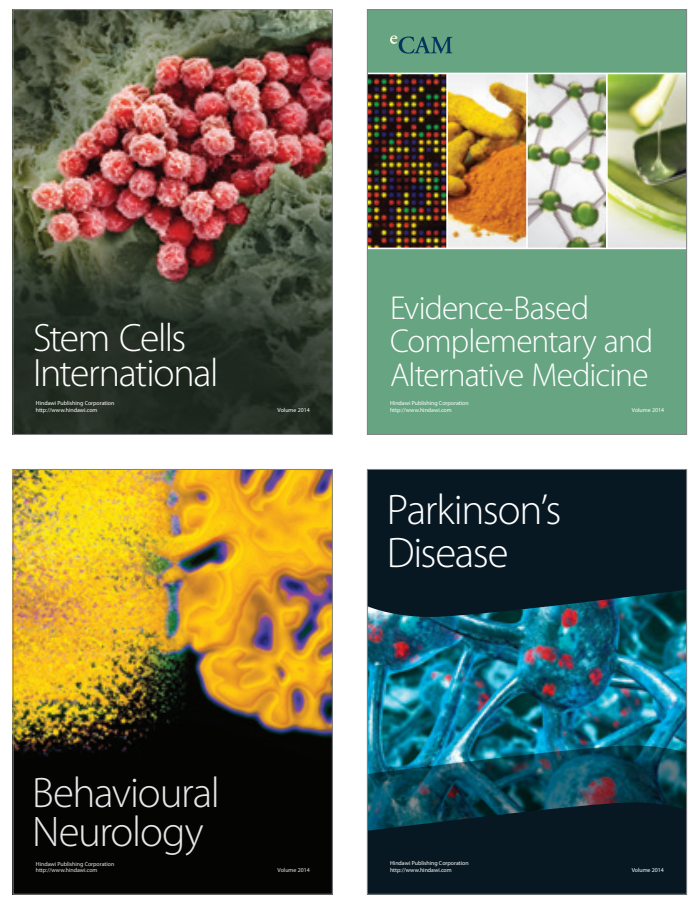
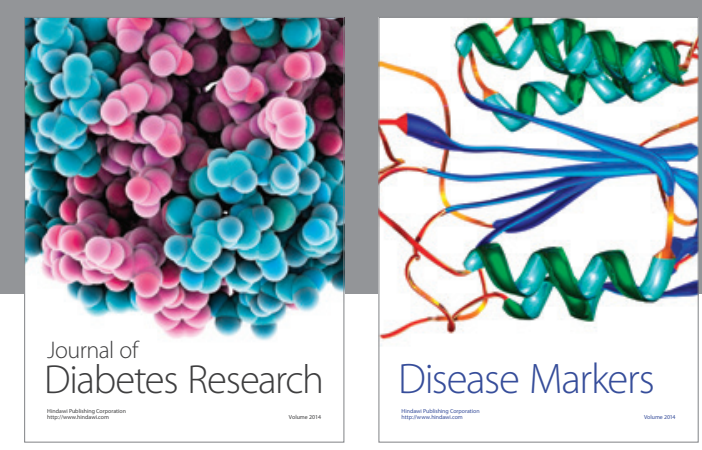

Disease Markers
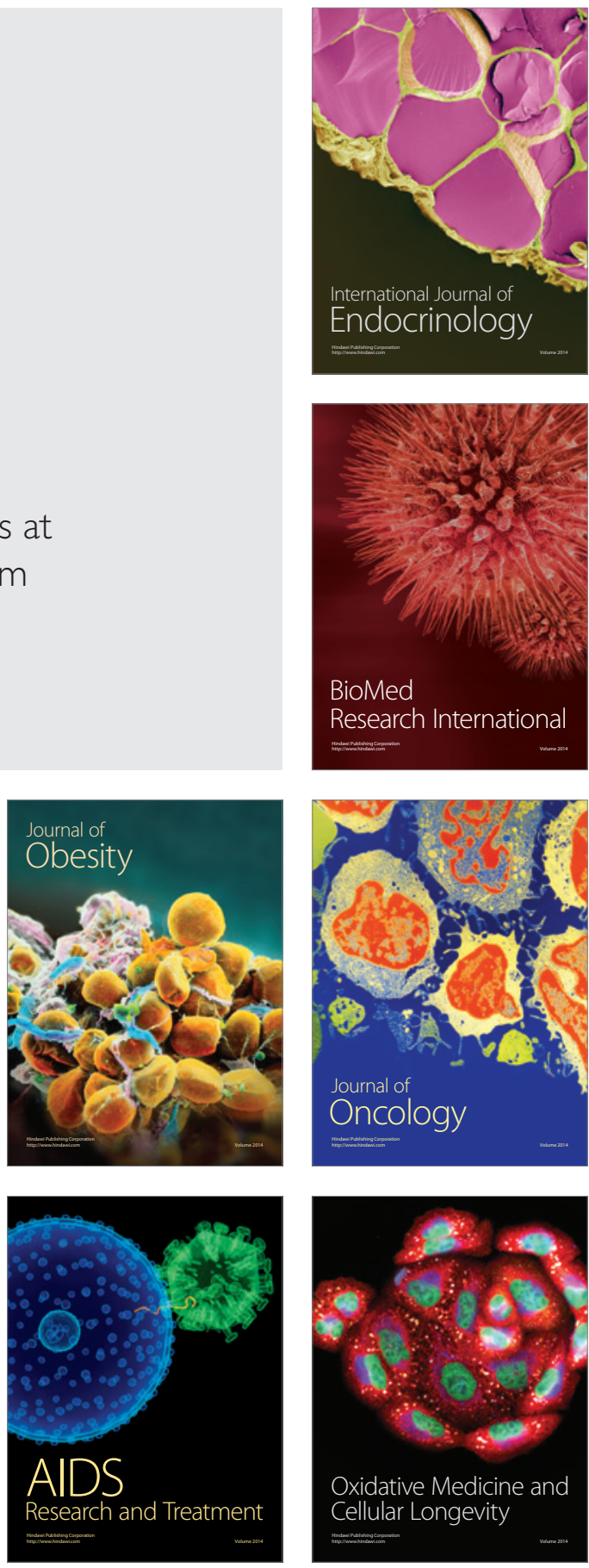